\title{
Effect of Sub-Lethal Doses of Smokeless Tobacco (Snuff) on Some Haemato-Rheological Parameters Using Albino Wistar Rats
}

\author{
Teddy C. Adias ${ }^{1}$, Anslem O. Ajugwo ${ }^{2, *}$, Tosan A. Erhabor ${ }^{3}$, Babatunde I. Adejumo ${ }^{4}$, Celestine C. Azikiwe ${ }^{5}$ \\ ${ }^{1}$ College of Health Technology Ogbia, Bayelsa State \\ ${ }^{2}$ Department of Haematology and Blood Transfusion, Madonna University Elele \\ ${ }^{3}$ Medical Laboratory Science Council of Nigeria (MLSCN) Abuja \\ ${ }^{4}$ Department of Medical Laboratory Science, University of Benin, Benin City \\ ${ }^{5}$ Department of Pharmacology, Anambra State University Uli \\ *Corresponding author: slemjugwo@yahoo.com
}

Received February 01, 2014; Revised March 24, 2014; Accepted April 29, 2014

\begin{abstract}
The tobacco plant (Nicotiana tabacum) has been used globally for several years as chewing tobacco, kreteck, dry snuff and in pipe. Snuff is a form of tobacco that is processed to fine grains and packaged either in cans or pouches. This study was carried out to investigate the effect of sub-lethal concentrations of orogastricallyadministered tobacco on some haematological and haemorrheological parameters of albino Wistar rats. Nineteen young albino Wistar rats with weights between 110-170 g were used for the study. The oral LD50 for the tobacco snuff concentration was determined as $10 \mathrm{mg}$ per $200 \mathrm{~g}$ rat body weight. The control group A was given $1 \mathrm{ml}$ of distilled water, while the experimental groups (B, C, D) were administered with tobacco snuff concentrations of 2.24 $\mathrm{mg}, 4.67 \mathrm{mg}$, and $6.77 \mathrm{mg}$ per body weight respectively, through an oral route with the aid of orogastric tube for 14 days. Blood samples were collected under chloroform anaesthesia and analysed for haematocrit, haemoglobin concentration, white blood cell (WBC), platelet counts, whole blood viscosity, plasma viscosity and serum viscosity. WBC was significantly increased $(\mathrm{p}<0.05)$ in group D $\left(13.43 \pm 4.26 \times 10^{9} /\right)$ as compared to the control $(10.0 \pm 3.12$ $\left.\mathrm{x} 10^{9} / \mathrm{l}\right)$. Platelet count was also significantly lower $(\mathrm{p}<0.05)$ in all the experimental groups B, C and D $(473 \pm 160.84$ $\left.\mathrm{x} 10^{9} /\right)$, $\left(357 \pm 66.55 \times 10^{9} / \mathrm{l}\right)$ and $\left(375.66 \pm 33.54 \times 10^{9} / 1\right)$ respectively as compared to the control $(758.25 \pm 113.41$ $\left.\mathrm{x} 10^{9} /\right)$. Whole blood viscosity was also significantly $(\mathrm{p}<0.05)$ increased. Smokeless tobacco may possibly affect clotting integrity and alter blood rheology.
\end{abstract}

Keywords: smokeless tobacco, haematocrit, haemoglobin, phytochemical, rheology, snuff

Cite This Article: Teddy C. Adias, Anslem O. Ajugwo, Tosan A. Erhabor, Babatunde I. Adejumo, and Celestine C. Azikiwe, "Effect of Sub-Lethal Doses of Smokeless Tobacco (Snuff) on Some Haemato-Rheological Parameters Using Albino Wistar Rats.” American Journal of Medical Sciences and Medicine, vol. 2, no. 3 (2014): 54-57. doi: 10.12691/ajmsm-2-3-1.

\section{Introduction}

Tobacco is the dried and processed leaves of the plant Nicotiana tobacum that is widely cultivated and commercially grown in many countries of the world. It is mostly consumed in the form of smoking, chewing, snuffing, or dipping tobacco. Its usage is an activity that is practiced by some 1.1 billion people, and up to one-third of the adult population [1]. The risks associated with smokeless tobacco use include cancer (particularly oral, esophageal and pancreatic cancers), heart disease, gum disease and oral lesions other than cancer [2]. The World Health Organization estimates that the use of tobacco caused 5.4 million deaths in 2004 and 100 million deaths over the course of the 20th century [3]. Similarly, the United States Center for Disease Control and Prevention describes tobacco use as "the single most important preventable risk to human health in developed countries and an important cause of premature death worldwide" [4].

One of the forms of smokeless tobacco is snuff. Snuff is a form of tobacco that is processed to fine grains and packaged either in cans or pouches. Its user takes a "pinch", “dip", or "quid" and places it between the lower lip or cheek and gum and suck on it [5]. Another route for the use of snuff, though rare is by sniffing, i.e. nasal use. This route is common among Nigerian users.

People in many regions and countries, including North America, northern Europe, India and other Asian countries, and parts of Africa, have a long history of using smokeless tobacco products. In Nigeria, particularly, tobacco snuff is utilized for cultural and traditional purposes. It is either inhaled through the nose or applied orally. Some addicts also chew the dried leaves. The frequency and speed of tobacco consumption and the effects which it has on the body is directly related to nicotine, the most prominent phytochemical found in tobacco. All tobacco products, 
including smokeless tobacco, contain nicotine, which is addictive [2]. The amount of nicotine per gram of tobacco ranged from 4.4 to 25 milligrams [6]. Other studies have shown that moist snuff had between 4.7 and 24.3 milligrams, dry snuff had between 10.5 and 24.8 milligrams, and chewing tobacco had between 3.4 and 39.7 milligrams per gram of tobacco [7]. Nicotine stays in the blood longer for users of smokeless tobacco than for smokers [4]. The level of nicotine in the blood depends on the amount of nicotine in the smokeless tobacco product, the tobacco cut size, the product's pH (a measure of its acidity or basicity) and other factors [6].

In the present study we investigated the effect of tobacco snuff on haematological parameters such as haematocrit; haemoglobin concentration, white blood cell (WBC) and platelet counts; and the haemorrheological parameters such as whole blood viscosity, plasma viscosity and serum viscosity.

\section{Materials and Methods}

\subsection{Subjects}

Nineteen (19) albino Wistar rats weighing between 110-190 g were procured from the animal house of Pharmacology and Toxicology, Faculty of Pharmacy Madonna University Elele Nigeria. The cages were sanitized every 48 hours and animal house cleaned every day. The rats were fed with standard grower's marsh (vital feeds) and clean tap water. They were exposed to 12-hour light and 12-hour darkness and allowed to acclimatize in this condition for a period of seven (7) days prior to experimental use.

\subsection{Smokeless Tobacco (Snuff)}

Commercially prepared tobacco snuff was bought from Elele Main market. The snuff was put in a plastic container and stored in a cool place. The lethal dose (LD50) concentration of the tobacco snuff was calculated as $10 \mathrm{mg} / 200 \mathrm{~g}$ rat body weight (b.w) using LD50 for nicotine in rats $(50 \mathrm{mg} / \mathrm{kg} \mathrm{b.w})$ as standard [8]. The concentrations of tobacco snuff used were calculated as $40 \%, 60 \%$ and $80 \%$.

\subsection{Ethical Approval}

The research was approved by the ethical committee of the institution. The standard, rules and regulations of use of animal for research purposes was strictly adhered to as approved by the committee.

\subsection{Animal Grouping and Experimental Protocol}

The animals were assigned into four (4) groups (A, B, $\mathrm{C}$ and $\mathrm{D}$ ) of five (5) rats per experimental group and four (4) for control according to their weights.

\begin{tabular}{|c|c|c|c|}
\multicolumn{2}{|c}{ Table 1. Distribution of the rats according to body weight and concentration required } \\
\hline Groups & Number of rats & Mean weight of rats(g) & Concentrations \\
\hline Group A (control) & 4 & 114.6 & Nil \\
Group B & 5 & 112.0 & $2.24 \mathrm{mg}$ in 1ml of distilled water. \\
Group C & 5 & 155.8 & $4.67 \mathrm{mg}$ in 1ml of distilled water. \\
Group D & 5 & 169.2 & $6.76 \mathrm{mg}$ in 1ml of distilled water \\
\hline
\end{tabular}

2.5. Preparation and Administration of Smokeless Tobacco (Snuff)

Stock solution for smokeless tobacco -stock solution was prepared according to the dose for the different percentage (40\%, $60 \%$ and $80 \%)$.

Note: If the LD50 is $10 \mathrm{mg} / 200 \mathrm{~g}$ body weight of the rat therefore $0.05 \mathrm{mg} / 1 \mathrm{~g}$ of rat.

Group B: 40\% standard: 40/100 x $0.05=0.02 \mathrm{mg}$.

Dose for group B: $40 \%$ standard $\mathrm{x}$ mean weight of rat (g).

$0.02 \mathrm{mg} x 112.0 \mathrm{~g}=2.24 \mathrm{mg}$.

If $2.24 \mathrm{mg}$ is dissolved in $1 \mathrm{ml}$ therefore $22.4 \mathrm{mg}$ will be dissolve in $10 \mathrm{ml}$ from which $1 \mathrm{ml}$ each would be administered to the experimental group (B).

This was done for group $\mathrm{C}$ and group D using $60 \%$ and $80 \%$ respectively.

Rats in the control group A were administered $1 \mathrm{ml}$ of distilled water and feed for the 14 days of the experiment. $2.24 \mathrm{mg}, 4.67 \mathrm{mg}$ and $6.76 \mathrm{mg}$ per body weight were measured and homogenously mixed in $1 \mathrm{ml}$ of distilled water and administered orogastrically to the experimental groups B, C and D respectively. This lasted for fourteen (14) days.

\subsection{Sample Collection and Analysis}

Blood samples were collected from unconscious rats during their fasting period, having been sedated with chloroform and their blood samples $(5 \mathrm{ml})$ were collected by ocular puncture, in a Tripotassium Ethylene Diamine Tetracetic acid ( $\mathrm{K}_{3}$-EDTA) anticoagulant container. Blood samples were analysed within six hours of collection using standard manual methods.

Serum, Plasma and Whole blood Viscosity [9]

\subsection{1. principle}

The test is based on the comparison of the rate of flow of plasma/whole blood and distilled water under equal pressure and constant temperature.

\subsubsection{Procedures}

The $1 \mathrm{~mL}$ syringe was clamped on the retort stand in a vertical position.

The well-mixed whole blood was suctioned by pulling the plunger of the syringe so that the plunger rises above the upper measuring line.

The suction was then released by gently pulling out the plunger and the whole blood was allowed to flow through the barrel.

A stop watch was started when the meniscus got to the upper measuring line, and the time required for the meniscus to pass the lower measuring line was determined, recorded and repeated twice.

The whole blood was removed from the syringes and then rinsed twice with normal saline and dried.

The syringe was reclamped and distilled water was determined the same way as whole blood. 


\subsubsection{Calculation of Results}

Plasma Viscosity $=\frac{\text { Flow time of plasma }(\text { secs })}{\text { Flow time of D / water }(\text { secs })}$
Whole blood viscosity $=\frac{\text { Flow time of whole blood (secs) }}{\text { Flow time of D / water }(\text { secs })}$

Packed Cell volume (PCV) and haemoglobin concentration were analyzed using microhaematocrit method and cyanmethaemoglobin method respectively. Visual counting method was used for WBC and platelet count using Turk's fluid and 1\% Ammonium oxalate respectively as diluting fluid [10].

\subsection{Data analysis}

The results gotten were analysed using Statistical Package for Social Science (SPSS) version 14. P values < 0.05 were considered significant while p values $>0.05$ were considered as not significant.

\section{Results}

Table 2. Mean \pm SD of some haematological parameters for the different groups

\begin{tabular}{|c|c|c|c|c|c|}
\hline Parameters & Group A (control) & Group B (40\%) & Group C (60\%) & Group D (80\%) & pvalue \\
\hline PCV (\%) & $35.5 \pm 10.43$ & $30.66 \pm 1.87$ & $37.0 \pm 2.44$ & $31.33 \pm 4.30$ & $\mathrm{P}>0.05$ \\
Hb (g/dl) & $10.72 \pm 10.92$ & $9.53 \pm 1.13$ & $11.63 \pm 1.48$ & $10.13 \pm 0.93$ & $\mathrm{P}>0.05$ \\
WBC (x10 $/ 1)$ & $10.0 \pm 3.12$ & $10.16 \pm 0.62$ & $11.2 \pm 1.76$ & $13.43 \pm 4.26$ & $\mathrm{P}<0.05$ \\
PLT count $\left(\mathrm{x} 10^{9} / \mathrm{l}\right)$ & $758.25 \pm 113.41$ & $473 \pm 160.84$ & $357 \pm 66.55$ & $375.66 \pm 33.54$ & $\mathrm{P}<0.05$ \\
\hline
\end{tabular}

Key:

PCV - Packed Cell Volume

$\mathrm{Hb}$ - Haemoglobin concentration

WBC - White blood cell count

PLT - Platelet count

Table 3. Mean \pm SD of some haemorheological parameters for the different groups

\begin{tabular}{|c|c|c|c|c|c|}
\hline Parameters & Group A (control ) & Group B (40\%) & Group C (60\%) & Group D (80\%) & pvalue \\
\hline RWBV (mpas) & $19.85 \pm 1.87$ & $20.23 \pm 5.46$ & $24.43 \pm 2.47$ & $24.4 \pm 1.34$ \\
RPV (mpas) & $6.62 \pm 0.14$ & $6.53 \pm 0.37$ & $6.96 \pm 0.18$ & $6.96 \pm 0.18$ \\
RSV (mpas) & $7.0 \pm 1.31$ & $6.53 \pm 0.37$ & $8.46 \pm 1.27$ & $\mathrm{P}>0.05$ \\
$\mathrm{P}$
\end{tabular}

Key:

RWBV - Relative whole blood viscosity

RPV - Relative plasma viscosity

RSV - Relative serum viscosity

\section{Discussion and conclusion}

From this study, the data indicated that at sub lethal doses of tobacco snuff consumption there was no significant difference in packed cell volume $(p>0.05)$ and haemoglobin concentration in the grouped rats administered different doses of smokeless tobacco (snuff) when compared to the control. Scientific literatures suggest that users of smokeless tobacco are similar to nontobacco users in terms of levels of packed cell volume [11]. In contrast, a decrease in PCV has been previously observed in Wistar rats after administering sub-lethal doses of tobacco leaf extracts [12]. Reference [12] recorded a significant decrease in PCV and haemoglobin concentration which does not agree with this study.

Total white blood cell count (WBC) was significantly increased $(\mathrm{P}<0.05)$ in group $\mathrm{D}\left(13.43 \pm 4.26 \times 10^{9} / \mathrm{l}\right)$ and group $C\left(11.2 \pm 1.76 \times 10^{9} / \mathrm{l}\right)$ when compared to that of control $\left(10.0 \pm 3.12 \times 10^{9} / 1\right)$. Tobacco use is associated with an increase in the white blood cell count. This association has been attributed to bronchopulmonary inflammation and/or infection [13]. Increased WBC counts in the present study may suggest chronic inflammatory changes in various tissues, due to exposure to toxic substances in tobacco snuff. Furthermore, the blood of tobacco smokers and snuffers is reported to contain significant concentration of nicotine [14]. Nicotine is known to cause the release of adrenalin and increases leukocytes in the peripheral blood, bone marrow and spleen [13]. The increase in WBC count in this study may also be attributed to increase in nicotine at higher doses of tobacco snuff, and subsequent release of adrenalin which mobilizes the leucocytes marginated in the blood capillaries.

The platelet count was significantly lower $(\mathrm{P}<0.05)$ in groups B, C and D with values of $\left(473 \pm 160.84 \times 10^{9} / \mathrm{l}\right)$, $\left(357 \pm 66.55 \times 10^{9} / 1\right)$ and $\left(375.66 \pm 33.54 \times 10^{9} / 1\right)$ respectively when compared to the control $\left(758.25 \pm 113.41 \times 10^{9} / 1\right)$. The reduced platelet count observed in this study may be due to platelet aggregation induced by increase in adrenaline release caused by the presence of nicotine in tobacco snuff. A potentiating effect of adrenalin on platelet aggregation has previously been demonstrated [15]. This study conforms to the investigation by $[4,12]$ whose research also show reduced platelet count. Abnormal reduction in platelet count will result in thrombocytopenia, affect vascular integrity, and cause increased bleeding and bruising in various tissues.

The whole blood viscosity was significantly increased $(\mathrm{P}<0.05)$ in groups $\mathrm{C}$ and $\mathrm{D}$ with values of $(24.43 \pm 2.47$ mpas) and (24.40 \pm 1.34 mpas) respectively when compared with the control (19.85 \pm 1.87 mpas). Nicotine which is a major constituent of tobacco, can raise blood pressure and pulse rate thereby increasing the blood viscosity leading to poor blood flow. Previous works have shown that tobacco users are at risk of heart attacks, strokes and chronic obstructive pulmonary disease (COPD) [16], which poor blood flow can be considered as a factor.

\section{Conclusion}

In conclusion, the present data indicated that consumption of tobacco snuff at sub-lethal doses in Wistar rats increased WBC counts, whole blood viscosity and reduced platelet count. These changes may put the body at 
risk of adverse health conditions such as inflammatory conditions, bleeding tendency, infections and poor blood flow.

\section{Conflict of Interest}

We declare that we have no conflict of interest. And no financial assistance was received in respect to this research.

\section{References}

[1] Gilman, S. L. and Xun, Z. (2004) Smoke - A Global History of Smoking. The University of Chicago Press, Chicago, IL, USA.

[2] International Agency for Research on Cancer (IARC) Working Group. (2007). Smokeless Tobacco and Some Tobacco-Specific $\mathrm{N}$-Nitrosamines. World Health Organization Monographs on the Evaluation of Carcinogenic Risks to Humans. 89: 345-346.

[3] World Health Organization. (2008). Report on the Global Tobacco Epidemic: The MPOWER Package. WHO Press, Geneva; Switzerland.

[4] Ukoha, U., Uchechukwu, D. and Stephen, M. (2012). The effect of sub-lethal doses of smokeless tobacco(snuff) on certain haematological and haemostatic parameters in wistar rats. Journal of Experimental and Integrative Medicine, 2 (3): 225-230.

[5] Mesembe, O., Bisong, S., Ekong, M. and Ekeoma, A. (2008). Neurobehavioural Activity In Albino Wistar Rats In The Open
Field Maze Following Long Term Tobacco Diet Ingestion. The Internet Journal of Neurology. 10 (2): 345-363.

[6] Richter, P., Hodge, K., Stanfill, S., Zhang, L. and Watson, C. (2008). Surveillance of moist snuff: total nicotine, moisture, $\mathrm{pH}$, un-ionized nicotine, and tobacco-specific nitrosamines. Nicotine Tobacco Result. 10: 1645-52.

[7] Djordjevic, M. V. and Doran, K. A. (2009). Nicotine content and delivery across tobacco products. Handbook Experimental Pharmacology; 192: 61-82.

[8] National institute for occupational safety and health (NIOSH). (1986). Registry of toxic effects of chemical substances (RTECS). 3 A: 3060-3424.

[9] Reid, H. and Ugwu, A. C. (1987). A simple technique of rapid determination of plasma and whole blood viscosity. Nigerian journal of physiological sciences. 3: 45-48.

[10] Cheesbrough, M. (2004). Laboratory practice in tropical countries part 2. Cambridge university press. Pg 299-312.

[11] Asplund, K. (2003). Smokeless tobacco and cardiovascular disease. Progressive Cardiovascular Disease 45: 383-394.

[12] Adeniyi, P. A. O., Ghazal, O. K. and Oyewopo, A. O. (2012). Haematological effects of aqueous extract of tobacco (Nicotiana tabacum) leaves in young Wistar rats. Retrieved October, 2013. From http://www.unilorin.edu.ng/ publications/gzali.

[13] Chang, E., Forsberg, E.C., Wu, J., Wang, B., Prohaska, S.S., Allsopp, R., Weissman, I. L. and Cooke, J. P. (2010) Cholinergic activation of hematopoietic stem cells: role in tobacco related disease. Vascular Medicine. 15: 375-85.

[14] Russell, M. A., Jarvis, M. J. and Feyerabend, C. (1980). A new age for snuff. Lancet. 315: 474-475.

[15] Mills, D.C.B. and Roberts, G.C.K. (1967). Effects of adrenaline on human blood platelets. Journal of Physiology. 193: 443-453.

[16] World Health Organization. (2008). The Global Burden of Disease: 2004 Update. WHO Press, Geneva, Switzerland. 